\title{
Biocontrol Potential of Fungal Endophytes against Fusarium oxysporum f. sp. cucumerinum Causing Wilt in Cucumber
}

\author{
Manzoor Ali Abro", ${ }^{1, *}$, Xiang Sun ${ }^{2}$, Xingchun $\mathrm{Li}^{2}$, Ghulam Hussain Jatoi (i) ${ }^{1}$, and Liang-Dong Guo ${ }^{2 *}$ \\ ${ }^{1}$ Department of Plant Pathology, Faculty of Crop Protection, Sindh Agriculture University Tandojam, Hyderabad \\ 70060, Pakistan \\ ${ }^{2}$ State Key Laboratory of Mycology, Institute of Microbiology, Chinese Academy of Sciences No. 1, Beijing 100101, \\ China
}

(Received on May 1, 2019; Revised on August 21, 2019; Accepted on August 22, 2019)

Endophytic fungi have received much attention as plant growth promoters as well as biological control agents against many plant pathogens. In this study, 30 endophytic fungal species, isolated from various plants in China, were evaluated using in vitro dual culture assay against Fusarium oxysporum f. sp. cucumerinum, causing wilt in cucumber. The results of the present study clearly showed that all the $\mathbf{3 0}$ endophytic fungal isolates were highly capable of inhibiting the mycelial colony growth of Fusarium oxysporum f. sp. cucumerinum with inhibition \% over $66 \%$ as compared to control treatments. Among all of them, 5 isolates were highly effective such as, Penicillium sp., Guignardia mangiferae, Hypocrea sp., Neurospora sp., Eupenicillium javanicum, and Lasiodiplodia theobromae, respectively. The Penicillium sp. and Hypocrea sp. were highly effective as compared to other isolates. From in vitro results 10 best isolates were selected for greenhouse studies. The results of the greenhouse studies showed

\footnotetext{
*Co-corresponding authors.

Manzoor Ali Abro

Phone, FAX) +92-333-7136569

E-mail)mabro@sau.edu.pk

Liang-Dong Guo

Phone, FAX) +86-(10)-64807510

E-mail)guold@im.ac.cn

ORCID

Ghulam Hussain Jatoi

https://orcid.org/0000-0002-7266-1567

(c) This is an Open Access article distributed under the terms of the Creative Commons Attribution Non-Commercial License (http:// creativecommons.org/licenses/by-nc/4.0) which permits unrestricted noncommercial use, distribution, and reproduction in any medium, provided the original work is properly cited.
}

Articles can be freely viewed online at www.ppjonline.org. that among all of them $\mathbf{3}$ endophytic fungal isolates successfully suppressed wilt severity when co-inoculation with pathogen Fusarium. oxysporum f. sp. cucumerinum. The endophytic fungi also enhanced plant growth parameters of the host plants, the antagonistic fungal isolates increased over all plant height, aerial fresh, and dry weight as compared to control.

Keywords : biocontrol, cucumber, Fusarium wilt, fungal endophytes

Handling Editor : Sang, Mee Kyung

Cucumber (Cucumis sativus L.) is one of the most important vegetable grown all over the world. However, this crop is attacked by several fungal diseases such as Fusarium wilt caused by Fusarium oxysporum, grey mould (Botrytis cinerea), damping-off (Fusarium spp.), anthracnose (Colletotrichum sp.), and leaf blight caused by Alternaria sp., but the Fusarium wilt caused by F. oxysporum f. sp. cucumerinum (FOC), is one of the most destructive diseases of cucumber crop worldwide (Martínez et al., 2003). This disease has very high importance due to its economic importance and this disease can cause huge losses to cucumber production, as this disease has been reported in many countries of the world and losses are up to $45 \%$ reported from many countries (McGovern, 2015). The most common disease symptoms appear as yellowing, stunting and wilting of the leaves and basal stem necrosis. The wilted leaves will dry out and fall off and many times the complete death of the plants may occur (Lim et al., 2006). Due to the soil-borne nature of the fungus and advancement of the pathogen to the parenchymatous cells, the management of cucumber Fusarium wilt is very difficult. Till to date no 
effective control method has yet been found to control this disease completely in cucumber production. Moreover, there are very few fungicides are available in the market which is effective against this pathogen but due to increasing environmental concerns and other constraints have limited their use (Vethavalli and Sudha, 2012). In addition, it has been shown that there is problem of resistant strains against these fungicides and emergence of new races of the pathogen in many countries have complicated the effective control of this devastating disease (Reis et al., 2005). Due to the side effects of indiscriminate and un-judicious use of chemical fungicides, environmental hazards, concerns to human health and inducing pathogen resistance to fungicides (Fan and Jackson, 1989; Norman, 1988), an alternative is the need of the world in changing global climate and for this, the use of natural biocontrol agents has become a very successful trend in integrated disease management (Backman and Sikora, 2008; Mei and Flinn, 2010). Other approaches are investigated, including the use of biocontrol agents (Singh et al., 1999; Xiang et al., 2016; Youssef et al., 2016; Zhang et al., 2014). Biological control of Fusarium wilt by means of different microorganisms (fungi or bacteria) could be used as a very useful alternative to synthetic fungicides as it has an attractive potential and eco-friendly since several endophytes have the ability to decrease disease severity in a better way through different mechanisms and check the progress of the pathogen within vascular tissues of the plants (Alabouvette et al., 1993; Lu et al., 2016; Patel et al., 2012; Paulitz et al., 1987). The biological control of this disease has become an attractive alternative to chemical fungicides and other conventional control methods. Several biocontrol agents mainly Bacillus, Trichoderma, Pseudomonas, nonpathogenic Fusarium, and Penicillium strains were evaluated to control Fusarium wilt, but still this lethal disease could not be controlled completely (Raza et al., 2017; Vos et al., 2014). In search of the potential biological control agent against several pathogens, one approach is recently being practiced, which is the isolation of different endophytes from diverse host species, because endophytic fungi have been reported to play a key role in numerous functions of the plants due to its nature of producing novel bioactive compounds. It has been repeatedly reported that endophytic fungi can be successfully used to protect plants against pests and diseases as these fungi producing protective metabolites, inducing resistance to the host plants to biotic and a biotic stress by improving their growth and by this directly or indirectly enhanced production and yield (Arnold et al., 2001; Kaul et al., 2012; Rai et al., 2014). These kinds of fungi hold massive potential for the development of eco-friendly and eco- nomically viable agricultural products (Lugtenberg et al., 2016). Endophytic fungi interact with their host plants in different ways, with each interaction giving rise to different alterations in both partners. Mutualistic fungi enhance the defense system of the plants to pathogens and improve the nutrient uptake of the host plants; therefore, the interaction between plants and endophytic fungi have the prime importance to understand the potential of fungi in preventing plant diseases (Zeilinger et al., 2016). Due to the ubiquitous nature of endophytic fungi, they may be present in every plant species and can be isolated from different organs of the plants, this group of organisms represents an abundant and dependable source of bioactive and chemically novel compounds with potential for exploitation in a wide variety of medical, agricultural and industrial arenas (Strobel, 2003). Endophytic fungi have been successfully implemented for their positive and sound effects on growth and development of the plants (Rania et al., 2016). And endophytic fungi associated with different host plants are just such a natural resources of biocontrol agents as these endophytic fungi have been explored as bio-factories of novel bioactive substances (Radić and Štrukelj, 2012). Considerable attention has been paid to the inhibitory activity of endophytic fungi against plant pathogenic fungi and their potential as biocontrol agents against plant diseases (Crozier et al., 2015; Hanada et al., 2010; Mejia et al., 2008). The main aim of this novel research work was to assess comprehensively the ability of endophytic fungi isolated from four different host plants to suppress the mycelial growth of FOC causing wilt in cucumber under in vitro and also to evaluate these endophytic fungi to control the cucumber Fusarium wilt in greenhouse conditions.

\section{Materials and Methods}

\section{Endophytic fungal species}

Sampling site and procedure. Healthy leaves and stems of tomato, mangrove, star anise, and agarwood were collected from various locations in China. For this, samples of these plants were collected from different sites of China. A total of ten healthy plant samples from each species were randomly chosen in the study site. The plants were approximately $20 \mathrm{~m}$ away from each other. One branch with leaves was randomly selected from each individual plant species. These samples were placed in zip-lock bags, brought to the laboratory and stored in a refrigerator at $4^{\circ} \mathrm{C}$ and used within $24 \mathrm{~h}$. The collected plant samples were thoroughly cleaned with tap water and then air-dried on filtered papers. Before processing for isolation, all the samples were surface-sterilized by immersion in $70 \%$ ethanol 
Table 1. Endophytic fungi isolated from 4 different host plants (tomato, mangrove, agarwood, and star anise) that were collected from various locations in China

\begin{tabular}{clcccc}
\hline No. & Host plants & $\begin{array}{c}\text { Plant } \\
\text { part }\end{array}$ & $\begin{array}{c}\text { No. of } \\
\text { samples }\end{array}$ & $\begin{array}{c}\text { Total No. of pieces } \\
\text { inoculated }\end{array}$ & $\begin{array}{c}\text { No. of strains } \\
\text { isolated }\end{array}$ \\
\hline 1 & Tomato (Lycopersicon esculentum $)$ & Stems & 10 & 160 & 114 \\
2 & Mangrove (Rhizophora mangle) & Stems & 10 & 160 & 124 \\
3 & Agarwood (Aquilaria sinensis) & Leaves & 10 & 160 & 134 \\
4 & Star anise (Illicium verum) & Leaves & 10 & 160 & 122 \\
\hline
\end{tabular}

for $1 \mathrm{~min}$, 5\% sodium hypochlorite solution for $3 \mathrm{~min}$, and then $70 \%$ ethanol for $30 \mathrm{~s}$, then the samples were dipped in sterile distilled water thrice to clean the samples properly and remove the effect of surface sterilization agents and dried on the sterilized filter papers. The isolation of endophytic fungi was conducted as previously described by (Guo et al., 2000; Wiyakrutta et al., 2004).

Isolation and identification. In brief, total of 30 fungal endophytes were isolated and identified from four host plant species such as mangrove, tomato, star anise, and agarwood. the identification of all the fungal isolates was done with the help of microscope and the different keys available in the laboratory, all the procedures were adopted as previously described by Guo et al. (2000) (Table 1).

Antagonistic assay. The biological control ability of the 30 identified fungi (Table 2) was selected for their in vitro activity against FOC causing wilt in cucumber crop by using the dual culture method on potato dextrose agar (PDA) plates. The pure culture of this pathogenic fungus was provided by Prof. Dr. Cai, Lei from State Key Laboratory of Mycology, Institute of Microbiology, Chinese Academy of Sciences, Beijing. These studies were conducted as the methods previously described by (Vethavalli and Sudha, 2012). In brief, for this purpose, a mycelial disk of $5 \mathrm{~mm}$ was carefully taken with the help of cork borer from the newly growing margins of the culture for every fungal strain of thirty endophytic taxa, and a same disk of the culture for FOC pathogen was placed $3 \mathrm{~cm}$ apart on the surface of PDA and allowed to grow at $25^{\circ} \mathrm{C}$. From 7 to 10 days after inoculation, the mycelia colony growth of the pathogen in the presence of endophytic fungus as well as alone in control treatment was calculated. Then, the growth inhibition $\%$ of each endophytic fungi versus each pathogen (IR) was calculated using the formula of (Eksteen et al., 2001) which was as under: IR $(\%)=[(\mathrm{C} 2$ $-\mathrm{C} 1) / \mathrm{C} 2] \times 100$, where $\mathrm{C} 2$ was diameter of the mycelia colony growth in control treatment, $\mathrm{C} 1$ was diameter of the mycelia colony growth of the pathogen in the presence of the antagonist. All the treatments were replicated five times and the whole experiment was repeated two times.

\section{In vivo biocontrol assay}

Preparation of spore suspension of endophytic fungi. Among the 30 endophytic fungal species, the 10 best performance fungal species, which gave the best growth inhibition \% against FOC of cucumber individually under in vitro conditions were selected for greenhouse studies against cucumber Fusarium wilt pathogen, FOC, as this disease has been considered as one of the most destructive diseases of cucumber worldwide and can cause huge losses to cucumber production all over the world. For this purpose, spore suspension of all the selected endophytic fungi for inoculating cucumber seeds were produced in Erlenmeyer flasks $(200 \mathrm{ml})$ containing $100 \mathrm{ml}$ of potato dextrose broth (PDB) medium which was autoclaved at $121^{\circ} \mathrm{C}$ for $15 \mathrm{~min}$ then allowed to cool down. Mycelia blocks of each endophytic fungus isolate were cut from one-week-old culture on PDA and aseptically transferred to PDB under laminar airflow. Five replicate flasks were used for each endophytic fungi isolate. Two flasks containing non-inoculating PDB were used as control. Flasks were incubated under laboratory conditions by using rotary shaker at 140 $\mathrm{rev} / \mathrm{min}$ and $25^{\circ} \mathrm{C}$ for 1 week to allow the fungal sporulation and to disperse spores throughout PDB medium. The fermentation broths of each individual endophytic fungus were mixed thoroughly for few minutes and then added with Tween-20. The fungal spores were harvested by filtering the spore suspension through a cheese muslin cloth to remove mycelia fragments. The spore density of sporulating fungi was then estimated using the hemocytometer and the suspension was standardized to provide a final spore concentration of $1.6 \times 10^{6}$ spores $/ \mathrm{ml}$.

Inoculation of seed with spore suspension. The cucumber cultivar, 'Fuyang F1-35', susceptible to Fusarium wilt caused by FOC was used throughout this study. For this, 
Table 2. Endophytic fungi isolated and identified from 4 different host plants (tomato, mangrove, star anise, and agarwood) that were collected from different locations in China

\begin{tabular}{|c|c|c|}
\hline No. & Host plant & Endophyte isolates \\
\hline 1 & Tomato (Lycopersicon esculentum) & Penicillium sp. \\
\hline 2 & Tomato (Lycopersicon esculentum) & Cladosporium sp. \\
\hline 3 & Tomato (Lycopersicon esculentum) & Ulocladium sp. \\
\hline 4 & Tomato (Lycopersicon esculentum) & Alternaria sp. \\
\hline 5 & Tomato (Lycopersicon esculentum) & Botryosporium sp. \\
\hline 6 & Tomato (Lycopersicon esculentum) & Verticillium sp. \\
\hline 7 & Tomato (Lycopersicon esculentum) & Aspergillus sp. \\
\hline 8 & Mangrove (Rhizophora stylosa) & Guignardia mangiferae \\
\hline 9 & Mangrove (Aegiceras corniculatum) & Fusarium incarnatum \\
\hline 10 & Mangrove (Aegiceras corniculatum) & Pestalotiopsis fici 07 \\
\hline 11 & Mangrove (Kandelia candel) & Corynespora cassiicola \\
\hline 12 & Mangrove (Aegiceras corniculatum) & Pestalotiopsis fici 06 \\
\hline 13 & Mangrove (Bruguiera gymnorrhiza) & Nigrospora oryzae \\
\hline 14 & Mangrove (Aegiceras corniculatum) & Pestalotiopsis mangiferae \\
\hline 15 & Mangrove (Aegiceras corniculatum) & Penicillium sclerotiorum \\
\hline 16 & Mangrove (Rhizophora stylosa) & Phomopsis sp. \\
\hline 17 & Mangrove (Aegiceras corniculatum) & Xylaria sp. \\
\hline 18 & Mangrove (Aegiceras corniculatum) & Pestalotiopsis humus \\
\hline 19 & Star anise (Illicium verum) & Trichoderma sp. \\
\hline 20 & Star anise (Illicium verum) & Arthrinium sp. \\
\hline 21 & Star anise (Illicium verum) & Colletotrichum gloeosporioides \\
\hline 22 & Star anise (Illicium verum) & Chaetomium subaffine \\
\hline 23 & Star anise (Illicium verum) & Phoma sp. \\
\hline 24 & Star anise (Illicium verum) & Cochliobolus sp. \\
\hline 25 & Agarwood (Aquilaria sinensis) & Hypocrea sp. \\
\hline 26 & Agarwood (Aquilaria sinensis) & Neurospora sp. \\
\hline 27 & Agarwood (Aquilaria sinensis) & Fusarium solani \\
\hline 28 & Agarwood (Aquilaria sinensis) & Eupenicillium javanicum \\
\hline 29 & Agarwood (Aquilaria sinensis) & Lasiodiplodia theobromae \\
\hline 30 & Agarwood (Aquilaria sinensis) & Paecilomyces lilacinus \\
\hline
\end{tabular}

seeds were surface-sterilized and properly dried with usual procedure of our lab, then seeds were soaked in spore suspension of each endophyte fungi for $12 \mathrm{~h}$, after seeds were planted on sterilized soil in nursery trays for 1-2 weeks in the greenhouse at $25^{\circ} \mathrm{C}$ and $85 \%$ relative humidity. Nursery trays were watered on alternate days and growth conditions were maintained in greenhouse. Young seedlings at the four-true-leaf growth stage were used throughout this study. These studies were conducted as previously described by (Posada and Vega, 2006).

Re-inoculation of cucumber plants with endophytes. Two weeks old cucumber plants, which were already colonized by each endophytic fungus were transplanted on other pots, then these seedlings were re-inoculated with $100 \mathrm{ml}$ spore suspension of each endophytic fungal species from fermentation broths by soil drenching method, for this three holes were made around the cucumber seedlings near the roots for successful colonization of the endophytes as previously described by Kim et al. (2007) and Costa et al. (2013). Three weeks after inoculation of endophytic fungi, re-isolation of each endophyte was done for confirmation of colonization. For this the few plants were uprooted from the treated plants and re-isolation was made by using same protocol for isolation of endophytes as previously reported by Miles et al. (2012) and Barretti et al. (2009).

Pathogen inoculation. For this purpose, spore suspension of FOC for inoculating cucumber plants was produced in Erlenmeyer flasks $(200 \mathrm{ml})$ containing $100 \mathrm{ml}$ of PDB medium which were autoclaved at $121^{\circ} \mathrm{C}$ for $15 \mathrm{~min}$ then allowed to cool down. Mycelia blocks of FOC were cut 
from one-week-old culture on PDA and aseptically transferred to PDB under laminar airflow, then these flasks were placed on rotary shaker at $140 \mathrm{rev} / \mathrm{min}$ and $25^{\circ} \mathrm{C}$ for one week to allow the fungal sporulation and to disperse spores throughout PDB medium. The FOC spores were harvested by filtering the spore suspension through a cheese muslin cloth to remove mycelia fragments and then spores were counted and adjusted to $10^{6}$ conidia/ml. The treated seedlings with each endophytic fungus were artificially inoculated with conidial suspension of FOC $\left(10^{6}\right.$ conidia/ml at $25 \mathrm{ml}$ per plant) four weeks post endophytic fungal treatment as a soil drench method by making three holes of 5 $\mathrm{cm}$ made at the base of cucumber plants treated with endophytes around the root by using $5 \mathrm{~cm}$ stick. Plants were left for $24 \mathrm{~h}$ after inoculation in the dark at $25^{\circ} \mathrm{C}$ and $90 \% \mathrm{RH}$. Uninoculated control plants were treated with water only (negative control). The plants inoculated only with pathogen spore suspension FOC were termed as positive control. After 24-h plants were transferred to the greenhouse for 1-2 weeks for disease development as described by Kim et al. (2001) and Anith et al. (2015). This individual experiment was conducted in Randomized Complete Design with five replications and the whole experiment was repeated two times.

Disease severity assessment. After 60 days of co-inoculation with biocontrol agents and pathogen the disease severity was recorded. The severity of Fusarium wilt was calculated by using $0-4$ disease severity scale:

$$
\text { Disease severity }=\frac{\text { Area of plant tissue infected }}{\text { Total area of tissue }} \times 100
$$

where, 0 , no symptoms of wilting (health leaves); $1,<25 \%$ of leaves showing yellowing and or necrosis; $2,26-50 \%$ of leaves showing yellowing and/or necrosis; $3,51-75 \%$ of leaves with yellowing and/or necrosis; and $4,76-100 \%$ of leaves with yellowing and/or necrosis. After that following parameters were recorded.

Plant growth assessment. At the end of the experiment, plant growth parameters of the host plant were also recorded such as plant height $(\mathrm{cm})$ aerial fresh and dry weights $(\mathrm{g})$ of infected and non-infected plants.

Analysis of data. Statistical analyses were carried out using Statistica software (Statsoft Inc., Tulsa, OK, USA). The ANOVA module was used for analyses of variance and multiple comparisons of means (tests of Neuman and Keuls).

\section{Results}

Isolation and identification of endophytic fungi from various host species. A total of 494 isolates of endophytic fungi were isolated from 640 tissue segments from the four host species of tomato, mangrove, star anise, and agarwood. Of these, 114 isolates were recovered from tomato stems, 124 from mangrove branches, 134 from agarwood leaves and 122 isolated from star anise (Table 1). A total of thirty isolates sporulated properly and identified into different taxa based on its morphological characteristics. Of the 30 endophytic taxa were isolated from four host plant species, mostly all belong to the Ascomycetes. Different endophyte taxa dominated the four host species. In tomato, the Cladosporium sp. was found in the highest frequency followed by Alternaria sp. and Penicillium sp. the stem segments showed higher percentage frequency of colonization of the endophytic fungi, while, Pestalotiopsis sp. was dominant in mangrove, Fusarium sp. was frequently found in agarwood and Trichoderma sp. was mostly found in star anise. The result of this study also showed that endophyte fungi were more prevalent in the stems and twigs as compared to leaves, whereas, Fusarium sp. was commonly present in most of the four-plant species.

In vitro evaluation of antagonistic activity of endophytes against $\boldsymbol{F}$. oxysporum. Antagonistic activity of all 30 different species of endophytic fungi isolated from four different host species was tested against FOC causing wilt of cucumber under in vitro conditions. The 5-day-old mycelia culture of the endophytic fungi and FOC pathogen by using dual culture techniques on PDA medium and by using the diameter of the growth inhibition \% was calculated against each endophyte vis-a-vis pathogen. In the present study, fungal endophytes isolated from all four host species showed considerable antagonistic activity against FOC. The result showed that all the thirty endophytic fungal species were capable of significant inhibition on the mycelia colony growth in culture with control values over $66 \%$ inhibition noted after 5-7 days of inoculation and incubated at $25^{\circ} \mathrm{C}$ as compared to untreated control, but the effects were the highest to the lowest depended upon each pathogen and endophyte species tested (Table 3). The mycelial colony growth of FOC was significantly different within the 30 endophytes but the 10 most effective endophytes fungal species were Penicillium sp., Guignardia mangiferae, Hypocrea sp., Neurospora sp., Eupenicillium javanicum, Lasiodiplodia theobromae, and Trichoderma sp., respectively. The most potent endophytic fungi against FOC 
Table 3. Antagonistic interaction between endophytic fungi and Fusarium oxysporum f. sp. cucumerinum (FOC) causal agent of wilt of cucumber

\begin{tabular}{|c|c|c|c|}
\hline No. & Host plant & Fungal endophyte & $\begin{array}{c}\text { Growth inhibition (\%) against } \\
\text { FOC }\end{array}$ \\
\hline 1 & Tomato & Penicillium sp. & $66.4 \pm 4.6$ \\
\hline 2 & Tomato & Cladosporium sp. & $38.2 \pm 7.4$ \\
\hline 3 & Tomato & Ulocladium sp. & $16.5 \pm 1.1$ \\
\hline 4 & Tomato & Alternaria sp. & $8.80 \pm 0.7$ \\
\hline 5 & Tomato & Botryosporium sp. & $13.3 \pm 2.5$ \\
\hline 6 & Tomato & Verticillium sp. & $2.70 \pm 2.4$ \\
\hline 7 & Tomato & Aspergillus sp. & $13.1 \pm 3.7$ \\
\hline 8 & Mangrove & Guignardia mangiferae & $47.3 \pm 3.1$ \\
\hline 9 & Mangrove & Fusarium incarnatum & $21.5 \pm 0.6$ \\
\hline 10 & Mangrove & Pestalotiopsis fici 07 & $28.6 \pm 0.7$ \\
\hline 11 & Mangrove & Corynespora cassiicola & $29.5 \pm 1.9$ \\
\hline 12 & Mangrove & Pestalotiopsis fici 06 & $26.0 \pm 2.4$ \\
\hline 13 & Mangrove & Nigrospora oryzae & $24.5 \pm 1.1$ \\
\hline 14 & Mangrove & Pestalotiopsis mangiferae & $34.1 \pm 1.4$ \\
\hline 15 & Mangrove & Penicillium sclerotiorum & $26.6 \pm 2.2$ \\
\hline 16 & Mangrove & Phomapsis sp. & $25.5 \pm 0.3$ \\
\hline 17 & Mangrove & Xylaria sp. & $19.0 \pm 0.5$ \\
\hline 18 & Mangrove & Pestalotiopsis humus & $28.4 \pm 3.0$ \\
\hline 19 & Star anise & Trichoderma sp. & $39.3 \pm 0.4$ \\
\hline 20 & Star anise & Arthrinium sp. & $27.1 \pm 1.3$ \\
\hline 21 & Star anise & Colletotrichum gloeosporioides & $16.3 \pm 1.2$ \\
\hline 22 & Star anise & Chaetomium subaffine & $19.5 \pm 0.9$ \\
\hline 23 & Star anise & Phoma sp. & $27.5 \pm 0.9$ \\
\hline 24 & Star anise & Cochliobolus sp. & $25.4 \pm 0.5$ \\
\hline 25 & Agarwood & Hypocrea sp. & $44.4 \pm 0.4$ \\
\hline 26 & Agarwood & Neurospora sp. & $43.1 \pm 1.0$ \\
\hline 27 & Agarwood & Fusarium solani & $35.1 \pm 0.6$ \\
\hline 28 & Agarwood & Eupenicillium javanicum & $43.3 \pm 0.7$ \\
\hline 29 & Agarwood & Lasiodiplodia theobromae & $40.2 \pm 0.3$ \\
\hline 30 & Agarwood & Paecilomyces lilacinus & $21.8 \pm 1.4$ \\
\hline
\end{tabular}

Growth inhibition \% by endophytic fungi isolated from 4 host species against $F$. oxysporum of cucumber. The mycelial disc of $5 \mathrm{~mm}$ of both the pathogenic fungus and endophytic fungus was deposited simultaneously in the potato dextrose agar plate and the dual culture was incubated for 1 week at $27^{\circ} \mathrm{C}$. Growth inhibition $\%$ of 30 endophytic fungi isolated from 4 different host plants was calculated as compared to control treatments. The entire experiment was repeated twice each with 5 replicates.

as shown in (Table 3), showed that maximum inhibition of mycelia growth of $F$. oxysporum was observed against Penicillium sp. (66.4\%), followed by Gugnardia mangiferae (47\%), Hypocrea sp. (44.2\%), Neurospora sp. (43.1\%), and Eupenicillium sp. (43.3\%), respectively. Overall, Penicillium sp. recovered from tomato stems and Hypocrea sp. isolated from agarwood showed the most potent inhibition activity against FOC under in vitro conditions.

Biocontrol efficacy of $\mathbf{1 0}$ best performed endophytic fungi in pot experiment. Ten fungal endophytes, which had shown the best antifungal activity against FOC causing wilt in cucumber crop under in vitro conditions, were tested against cucumber Fusarium wilt pathogen plants inoculated with FOC in pot experiment in greenhouse conditions. After analysis of variance, the results showed that there was a significant decrease in the severity of Fusarium wilt noted 60 days after co-inoculation of endophytes with FOC but the effects were depended on each antagonistic fungus tested. Generally, several endophytic fungi have significantly decreased the severity of cucumber Fusarium wilt on 0-4 disease severity scale (Table 4). Two weeks 

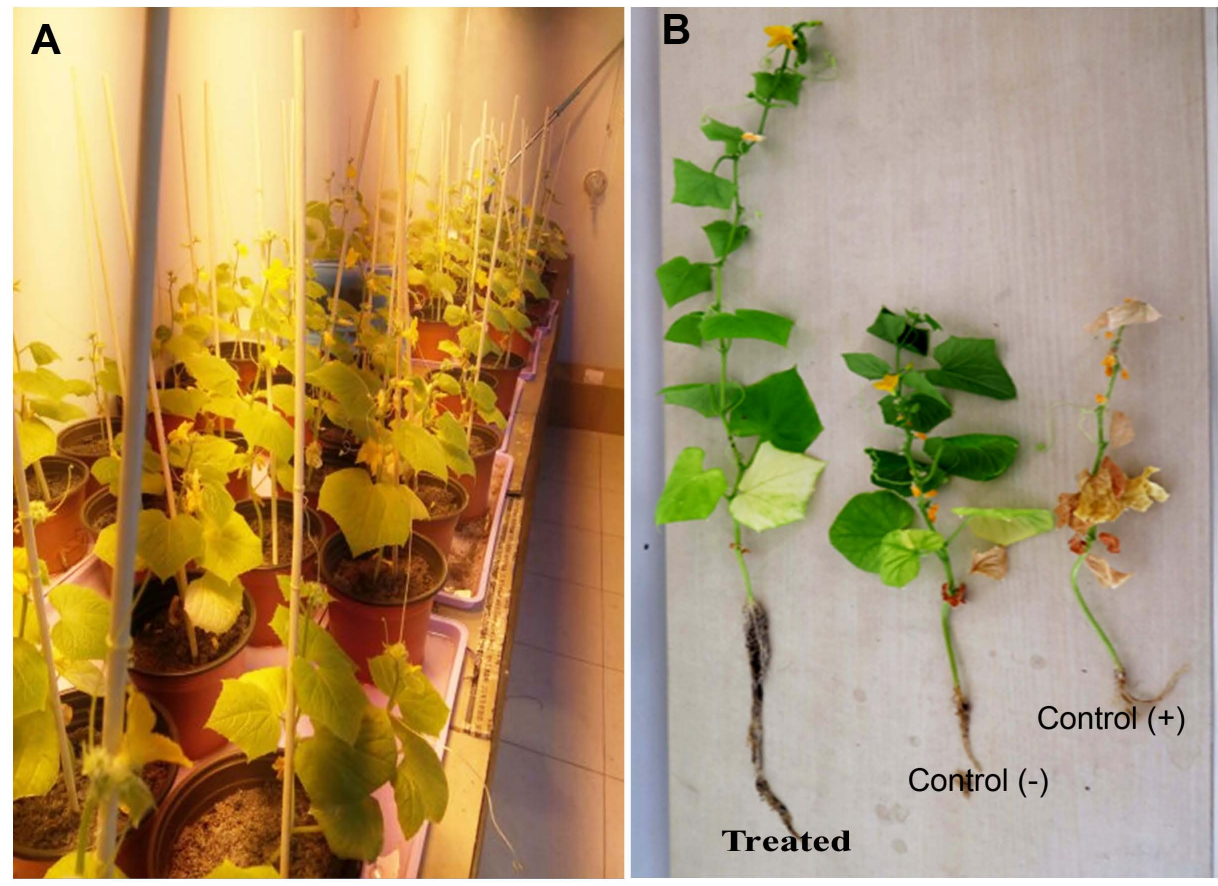

Fig. 1. Effect of endophytic fungi on plant growth and development of cucumber plants and suppression of Fusarium wilt disease severity on cucumber 'Fuyang F1-35'. (A) Plants incubated in greenhouse in controlled conditions. (B) Plants treated with different endophytic fungi. Control (-) uninoculated with pathogen and untreated. Control $(+)$ inoculated with F. oxysporum f. sp. cucumerinum and untreated. All the treated plants were compared to the infected and noninfected controls noted 60 days post inoculation.

after inoculation of the spore suspension of the pathogen the cucumber plants in infected control treatments started showing the first external wilt symptoms like yellowing of leaves, symptoms of the wilt were appeared as leaf chlorosis and first they were observed in older leaves and then spread to younger leaves (Fig. 1). After seven weeks of inoculation, at this stage $70-85 \%$ of the plants in the infected control treatments showed severe wilt symptoms and the disease severity reached up to 3.60 on $0-4$ disease severity scale (Fig. 1), but in endophyte treated plants the plantlets showed mild symptoms and the disease severity was much lower 1.20 on 0-4 severity scale as compared to the infected control treatment (Table 4). The results also showed that Penicillium sp. which was isolated from the stems of tomato, Lasiodiplodia theobromae and Hypocrea sp. isolated from agarwood were found to be highly effec-

Table 4. Effect of endophytic fungi isolated from four different host species (tomato, mangrove, agarwood, and star anise) tissues on Fusarium wilt severity

\begin{tabular}{cllcccc}
\hline No. & Host crop & Fungal endophyte & $\begin{array}{c}\text { Disease severity } \\
(0-4)\end{array}$ & Plant height $(\mathrm{cm})$ & Fresh weight $(\mathrm{g})$ & Dry weight $(\mathrm{g})$ \\
\hline 1 & Tomato & Penicillium sp. & $1.20 \pm 0.4 \mathrm{bc}$ & $85.26 \pm 0.6 \mathrm{a}$ & $17.29 \pm 0.5 \mathrm{a}$ & $1.619 \pm 0.1 \mathrm{a}$ \\
2 & Agarwood & Hypocrea sp. & $1.40 \pm 0.3 \mathrm{bc}$ & $68.64 \pm 0.4 \mathrm{ab}$ & $13.90 \pm 0.4 \mathrm{ab}$ & $1.355 \pm 0.1 \mathrm{ab}$ \\
3 & Mangrove & Guignardia mangiferae & $2.20 \pm 0.4 \mathrm{ab}$ & $57.58 \pm 0.4 \mathrm{ab}$ & $12.12 \pm 0.5 \mathrm{ab}$ & $1.058 \pm 0.1 \mathrm{abc}$ \\
4 & Star anise & Trichoderma sp. & $2.20 \pm 0.4 \mathrm{ab}$ & $62.34 \pm 0.6 \mathrm{ab}$ & $08.74 \pm 0.5 \mathrm{ab}$ & $0.834 \pm 0.2 \mathrm{bc}$ \\
5 & Agarwood & Neurospora sp. & $2.40 \pm 0.5 \mathrm{ab}$ & $64.86 \pm 0.4 \mathrm{ab}$ & $08.91 \pm 0.3 \mathrm{ab}$ & $0.971 \pm 0.1 \mathrm{bc}$ \\
6 & Agarwood & Eupenicillium javanicum & $2.00 \pm 0.5 \mathrm{ab}$ & $63.52 \pm 0.4 \mathrm{~b}$ & $08.71 \pm 0.5 \mathrm{ab}$ & $0.688 \pm 0.2 \mathrm{bc}$ \\
7 & Agarwood & Lasiodiplodia theobromae & $1.20 \pm 0.4 \mathrm{bc}$ & $71.52 \pm 0.6 \mathrm{ab}$ & $16.18 \pm 0.4 \mathrm{ab}$ & $1.413 \pm 0.1 \mathrm{ab}$ \\
8 & Mangrove & Pestalotiopsis humus & $1.40 \pm 0.4 \mathrm{bc}$ & $60.08 \pm 0.4 \mathrm{ab}$ & $13.60 \pm 0.5 \mathrm{ab}$ & $1.151 \pm 0.1 \mathrm{abc}$ \\
9 & Tomato & Cladosporium sp. & $2.60 \pm 0.5 \mathrm{ab}$ & $56.65 \pm 0.4 \mathrm{ab}$ & $10.85 \pm 0.5 \mathrm{ab}$ & $0.985 \pm 0.2 \mathrm{abc}$ \\
10 & Agarwood & Fusarium solani & $2.60 \pm 0.4 \mathrm{ab}$ & $57.80 \pm 0.6 \mathrm{ab}$ & $08.53 \pm 0.4 \mathrm{ab}$ & $0.712 \pm 0.2 \mathrm{bc}$ \\
11 & Control $(+)$ & Only pathogen & $3.60 \pm 0.4 \mathrm{a}$ & $40.32 \pm 0.5 \mathrm{~b}$ & $05.74 \pm 0.3 \mathrm{~b}$ & $0.563 \pm 0.1 \mathrm{c}$ \\
12 & Control $(-)$ & No endophyte + no pathogen & $0.00 \pm 0.5 \mathrm{c}$ & $54.02 \pm 0.4 \mathrm{ab}$ & $07.62 \pm 0.4 \mathrm{ab}$ & $0.640 \pm 0.1 \mathrm{abc}$ \\
\hline
\end{tabular}

${ }^{a}$ Control (-) uninoculated with pathogen and untreated. Control (+) inoculated with Fusarium oxysporum f. sp. cucumerinum and untreated. For each column, values followed by the same letters are not significantly different according to Tukey test at $P<0.05$.

${ }^{b}$ Disease severity scale (0-4) and plant growth parameters (plant height, aerial fresh, and dry weights) of cucumber cv, 'Fuyang F1-35' observed 60 days post inoculation with $F$. oxysporum f. sp. cucumerinum as compared to infected and non-infected control treatments. 
tive in suppressing the Fusarium wilt severity as compared to the infected control treatments (Table 4). The results also showed that there was a highly significant effect $(P<0.05)$ of endophytic fungi on the plant growth parameters of the cucumber plants as compared to the infected and noninfected control treatments. Sixty days after co-inoculation with FOC, all the endophytic fungi have significantly increased the plant height and aerial fresh and dry weights of the cucumber plants as compared to the infected and noninfected control treatments. The highest plant height was observed in plants treated with Penicillium sp. $(85.24 \mathrm{~cm})$ followed by plants treated with Lasiodiplodia theobromae $(71.56 \mathrm{~cm})$ and Hypocrea sp. $(68.64 \mathrm{~cm})$, respectively. Whereas, the plants treated with Penicillium sp. and Lasiodiplodia theobromae also have the highest aerial fresh and dry weights as compared to the infected and non-infected control treatments. The highest aerial fresh and dry weights increase was achieved by means of Penicillium sp. (17.29 and 1.169) isolated from tomato stems and Lasiodiplodia theobromae (16.18 and 1.413), respectively recovered from agarwood treated plants (Table 4).

\section{Discussion}

Several endophytic fungal species are now successfully tested as biocontrol agents against plant pathogenic fungi as well as for plant growth promotion. This strategy is very promising for the improvement of crop productivity and as an alternative to chemical fungicides and synthetic fertilizers (Wang et al., 2016; Wu et al., 2016). Numerous attempts were made to control wilt disease through biocontrol agents using endophytic fungi and bacteria (Aydi Ben Abdallah et al., 2016; Hong et al., 2007; Raza et al., 2017; Saravanakumar et al., 2016). On the other hand, the utilization of different endophytic fungi isolated from diverse host plant species as biocontrol agents against fungal pathogens of cucumber crop in in vitro and in greenhouse conditions was seldom found (Raza et al., 2017). In the present study, endophytic fungi were screened for their potential to inhibit the growth of FOC causing wilt in cucumber and to suppress the cucumber Fusarium wilt and for promotion of plant growth. The novelty and special interest in our studies is that, these endophytic fungi were isolated from four different host species collected from different agro-ecological zones of China. A lot of studies have shown previously that these host plants may be valuable as prospective sources of bioactive compounds and biological control agents against plant diseases (Rai et al., 2014). However, a few reports were available on the use of endophytic fungi isolated from tomato, mangrove, star anise, and agarwood plants as ef- ficient source for the isolation of biocontrol agents. On numerous occasions for example, several endophytic fungi such as Alternaria, Cladosporium, Curvularia, Fusarium, Phaeoacremonium, and Trichoderma have been isolated mainly from the star anise, tomato, mangrove (Debbab et al., 2013), and agarwood (Premalatha and Kalra, 2013) and were used as biocontrol agents against pathogenic fungi.

In the present study, thirty endophytic fungi isolated from four different host species evaluated in in vitro for their antagonistic potential toward FOC causing wilt of cucumber crop, our results clearly showed that, among thirty endophytes tested Penicillium sp., Guignardia mangiferae, Hypocrea sp., Neurospora sp., Trichoderma sp. and has significantly reduced the mycelial growth of FOC with growth inhibition $\%$ that ranged up to $66.4 \%$ respectively but the effects were depending on each endophyte tested. Similar effects were reported by Saravanakumar et al. (2016), Zhang et al. (2014), and Xiang et al. (2016) using endophytic fungi isolated from cucumber and other medicinal plants and identified as Trichoderma, Alternaria, Phomopsis, Colletotrichum, Phoma, and Acremonium. Endophytic fungi have the ability to control plant pathogens in in vitro conditions with diverse mechanisms. Moreover, in another study an endophytic fungus isolated from Muscodor albus effectively controlled the $P$. ultimum under in vitro via the production of volatile compounds. Tenday-old cultures of endophyte killed $P$. ultimum in vitro (Worapong and Strobel, 2009). Moreover, the recent study indicated that when Debaryomyces hansenii was tested against four strains of pathogenic fungi, the results showed that it decreased the mycelia colony growth of the four pathogenic fungi such as Aspergillus sp., Fusarium proliferatum, and $F$. subglutinans from $97-98.3 \%$ by producing volatile compounds (Medina-Córdova et al., 2016). In addition when T. harzianum and $S$. proteamaculans were screened against Rhizoctonia solani, both endophytic fungi were highly effective to reduce the growth of pathogen in in vitro by overgrown the pathogen mycelia growth (Youssef et al., 2016), likewise, when Beauveria sp. was tested against soil-borne plant pathogenic fungi such as Pythium, Rhizoctonia, and Fusarium in in vitro conditions this endophyte restrict the pathogen growth by producing some bioactive metabolites (Ownley et al., 2010). Some other workers also reported the key role played by endophytes against pathogenic fungi as Miles et al. (2012) investigated the biological control potential of 100 fungal endophytes associated with Espeletia sp. against common crop pathogens, including Rhizoctonia solani, Botrytis cinerea, Fusarium oxysporum, and Phytophthora infestans, their results indicated that all endophytic strains were high- 
ly effective against many pathogens tested and the most highly effective strains were identified as Aureobasidium pullulans and Paraconiothyrium sporulosum and that the inhibitory effect was due to the production of endophytic bioactive metabolites. Other species, like well-known biological control agent Trichoderma can inhibit the growth of many pathogenic fungi by producing metabolites (Bae et al., 2016). These results suggest that tomato, mangrove, star anise and agarwood harbors diversify endophytic fungi, from which potential biocontrol agents against destructive plant pathogens like F. oxysporum, Verticillium, and $B$. cinerea, and for promoting growth of cucumber can be screened as these plants have the potential to harbor the endophytic fungi with promising source of different and structurally unprecedented bioactive natural products is unquestionable and continues to attract considerable attention (Debbab et al., 2013; Premalatha and Kalra, 2013).

Our results also showed that there was highly significant decrease in the severity of Fusarium wilt, observed 60 days after inoculation with FOC, but the effects were depending on the endophytic fungal treatments tested. Penicillium sp. which was isolated from the stems of tomato, Hypocrea sp. and Lasiodiplodia theobromae isolated from agarwood were highly effective in reducing wilt symptoms as compared to FOC inoculated and the infected and non-infected untreated control plants. In the same way, Saravanakumar et al. (2016) screened 100 strains of Trichoderma as potential biocontrol agents against Fusarium wilt in cucumber both under in vitro and in vivo methods, 10 isolates inhibited the growth of the pathogen with more than $85 \%$ inhibition and in greenhouse trials 1 strain Trichoderma asperellum was able to decrease the severity of Fusarium wilt by at least $71.67 \%$. Moreover, T. polysporum was highly effective in suppressing melon wilt with highest efficacy to control and enhance the fruit quality and yield under field conditions (Gava and Pinto, 2016). Moreover, Trichoderma sp. have the capability to induce the antioxidant enzymes in plants under stress conditions after pathogen challenge as well as increased the plant fresh weight and seedling growth of tomato plants (Prabhukarthikeyan et al., 2014; Youssef et al., 2016) also found that application of Beauveria sp. effectively reduced wilt disease in tomato plants. In the same sense, some bacterial strains also suppressed the cucumber Fusarium wilt severity as Streptomyces albospinus was found to be the promising biocontrol agent for cucumber wilt (Wang et al., 2016). In another study reported that Bacillus sp. can inhibit the cucumber Fusarium wilt 30 days after inoculation and some strains giving 20-79\% control efficacy (Hong et al., 2007). As reported in recent studies, endophytic fungi can successfully suppress the fungal plant pathogens through various means including the promotion of plant growth and by induced resistance to the plants (Lugtenberg et al., 2016; Ownley et al., 2010; Youssef et al., 2016). Meanwhile, we cannot rule out other mechanisms, as some Trichoderma spp. have the ability in triggering plant defense mechanisms as some reports suggested that the expression levels of defense-related genes, chitinase (SlChi3), beta-1,3-glucanase (SlGluA), and PR-1 (SlPR-1a) were significantly increased in the stems and roots of Trichoderma treated, Fusarium oxysporum f. sp. lycopersici infected plants (El Komy et al., 2016).

Conclusion. The evaluation of the endophytic fungi associated with surface-sterilized tissues of four different host species with antifungal potential against FOC causing wilt of cucumber crop under in vitro conditions led to the selection of three the most promising biocontrol agents like Penicillium sp., Hypocrea sp., and Lasiodiplodia theobromae were found very effective in reducing cucumber Fusarium wilt severity and improvement of cucumber plant growth. Moreover, these results also confirmed that tomato, mangrove, star anise, and agarwood are very important host species, which harbor important genera of endophytic fungi and these plants are the potentially major and key source for isolation of most effective endophytic fungi, which has the dual benefits for the plants, both as biocontrol agents and as plant growth promoters. Further studies are required to elucidate the mechanisms involved at cellular and molecular level.

\section{Acknowledgments}

This work was financially supported by Chinese Academy of Sciences CAS in the category of visiting Professorship for visiting Scientists Grant No 2016VBB058 and by the Strategic Priority Research Program of the Chinese Academy of Sciences (no. XDB31000000). The authors wish to thank Prof. Cai, Lei from State Key Laboratory of Mycology, CAS, Beijing for providing culture of pathogenic fungi. The authors also wish to thank all the staff of the mycorhizal and fungal endophytes research group at State Key Laboratory of Mycology, Institute of Microbiology, Chinese Academy of Sciences, Beijing, China, for their warm welcome and providing pleasant working conditions.

\section{References}

Alabouvette, C., Lemanceau, P. and Steinberg, C. 1993. Recent advances in the biological-control of Fusarium wilts. Pestic. Sci. 37:365-373. 
Anith, K. N., Sreekumar, A. and Sreekumar, J. 2015. The growth of tomato seedlings inoculated with co-cultivated Piriformospora indica and Bacillus pumilus. Symbiosis 65:9-16.

Arnold, A. E., Maynard, Z. and Gilbert, G. S. 2001. Fungal endophytes in dicotyledonous neotropical trees: patterns of abundance and diversity. Mycol. Res. 105:1502-1507.

Aydi Ben Abdallah, R., Mokni-Tlili, S., Nefzi, A., JabnounKhiareddine, H. and Daami-Remadi, M. 2016. Biocontrol of Fusarium wilt and growth promotion of tomato plants using endophytic bacteria isolated from Nicotiana glauca organs. Biol. Control 97:80-88.

Backman, P. A. and Sikora, R. A. 2008. Endophytes: An emerging tool for biological control. Biol. Control 46:1-3.

Bae, S.-J., Mohanta, T. K., Chung, J. Y., Ryu, M., Park, G., Shim, S., Hong, S.-B., Seo, H., Bae, D.-W., Bae, I., Kim, J.-J. and Bae, H. 2016. Trichoderma metabolites as biological control agents against Phytophthora pathogens. Biol. Control 92:128138.

Barretti, P. B., Romeiro, R. S., Mizubuti, E. S. G. and de Souza, J. T. 2009. Screening of endophytic bacteria isolated from tomato plants as potencial biocontrol agents and growth promotion. Ciênc. Agrotec. 33 Suppl:2038-2044 (in Portuguese).

Costa, F. G., Zucchi, T. D. and de Melo, I. S. 2013. Biological control of phytopathogenic fungi by endophytic actinomycetes isolated from maize (Zea mays L.). Braz. Arch. Biol. Technol. 56:948-955.

Crozier, J., Arroyo, C., Morales, H., Melnick, R. L., Strem, M. D., Vinyard, B. T., Collins, R., Holmes, K. A. and Bailey, B. A. 2015. The influence of formulation on Trichoderma biological activity and frosty pod rot management in Theobroma cacao. Plant Pathol. 64:1385-1395.

Debbab, A., Aly, A. H. and Proksch, P. 2013. Mangrove derived fungal endophytes: a chemical and biological perception. Fungal Divers. 61:1-27.

Eksteen, D., Pretorius, J. C., Nieuwoudt, T. D. and Zietsman, P. C. 2001. Mycelial growth inhibition of plant pathogenic fungi by extracts of South African plant species. Ann. Appl. Biol. 139:243-249.

El Komy, M. H., Saleh, A. A., Ibrahim, Y. E., Hamad, Y. K. and Molan, Y. Y. 2016. Trichoderma asperellum strains confer tomato protection and induce its defense-related genes against the Fusarium wilt pathogen. Trop. Plant Pathol. 41:277-287.

Fan, A. M. and Jackson, R. J. 1989. Pesticides and food safety. Regul. Toxicol. Pharmacol. 9:158-174.

Gava, C. A. T. and Pinto, J. M. 2016. Biocontrol of melon wilt caused by Fusarium oxysporum Schlect f. sp melonis using seed treatment with Trichoderma spp. and liquid compost. Biol. Control 97:13-20.

Guo, L. D., Hyde, K. D. and Liew, E. C. Y. 2000. Identification of endophytic fungi from Livistona chinensis based on morphology and rDNA sequences. New Phytol. 147:617-630.

Hanada, R. E., Pomella, A. W. V., Costa, H. S., Bezerra, J. L., Loguercio, L. L. and Pereira, J. O. 2010. Endophytic fungal diversity in Theobroma cacao (cacao) and T. grandiflorum (cupuaçu) trees and their potential for growth promotion and biocontrol of black-pod disease. Fungal Biol. 114:901-910.

Hong, P.-X., Qiu, S.-X., Chen, H., Zhao, X.-D. and Hu, F.-P. 2007. Isolation and screening of endophytic antagonistic bacteria from four species of Solanaceae. J. Fujian Agric. For. Univ. 36:347-351 (in Chinese).

Kaul, S., Gupta, S., Ahmed, M. and Dhar, M. K. 2012. Endophytic fungi from medicinal plants: a treasure hunt for bioactive metabolites. Phytochem. Rev. 11:487-505.

Kim, H.-Y., Choi, G. J., Lee, H. B., Lee, S. W., Lim, H. K., Jang, K. S., Son, S. W., Lee, S. O., Cho, K. Y., Sung, N. D. and Kim, J.-C. 2007. Some fungal endophytes from vegetable crops and their anti-oomycete activities against tomato late blight. Lett. Appl. Microbiol. 44:332-337.

Kim, J.-C., Choi, G. J., Park, J.-H., Kim, H. T. and Cho, K. Y. 2001. Activity against plant pathogenic fungi of phomalactone isolated from Nigrospora sphaerica. Pest Manag. Sci. 57:554-559.

Lim, G. T. T., Wang, G.-P., Hemming, M. N., Basuki, S., McGrath, D. J., Carroll, B. J. and Jones, D. A. 2006. Mapping the $I-3$ gene for resistance to Fusarium wilt in tomato: application of an I-3 marker in tomato improvement and progress towards the cloning of I-3. Australas. Plant Pathol. 35:671680.

Lu, D., Ma, Z., Xu, X. and Yu, X. 2016. Isolation and identification of biocontrol agent Streptomyces rimosus M527 against Fusarium oxysporum f. sp. cucumerinum. J. Basic Microbiol. 56:929-933.

Lugtenberg, B. J., Caradus, J. R. and Johnson, L. J. 2016. Fungal endophytes for sustainable crop production. FEMS Microbiol. Ecol. 92:fiw194.

Martínez, R., Aguilar, M. I., Guirado, M. L., Álvarez, A. and Gómez, J. 2003. First report of fusarium wilt of cucumber caused by Fusarium oxysporum in Spain. Plant Pathol. 52:410.

McGovern, R. J. 2015. Management of tomato diseases caused by Fusarium oxysporum. Crop Prot. 73:78-92.

Medina-Córdova, N., López-Aguilar, R., Ascencio, F., Castellanos, T., Campa-Córdova, A. I. and Angulo, C. 2016. Biocontrol activity of the marine yeast Debaryomyces hansenii against phytopathogenic fungi and its ability to inhibit mycotoxins production in maize grain (Zea mays L.). Biol. Control 97:70-79.

Mei, C. and Flinn, B. S. 2010. The use of beneficial microbial endophytes for plant biomass and stress tolerance improvement. Recent Pat. Biotechnol. 4:81-95.

Mejía, L. C., Rojas, E. I., Maynard, Z., van Bael, S., Arnold, A. E., Hebbar, P., Samuels, G. J., Robbins, N. and Herre, E. A. 2008. Endophytic fungi as biocontrol agents of Theobroma cacao pathogens. Biol. Control 46:4-14.

Miles, L. A., Lopera, C. A., González, S., de García, M. C. C., Franco, A. E. and Restrepo, S. 2012. Exploring the biocontrol potential of fungal endophytes from an Andean Colombian Paramo ecosystem. BioControl 57:697-710. 
Norman, C. 1988. EPA sets new policy on pesticide cancer risks. Science 242:366-367.

Ownley, B. H., Gwinn, K. D. and Vega, F. E. 2010. Endophytic fungal entomopathogens with activity against plant pathogens: ecology and evolution. BioControl 55:113-128.

Patel, H. A., Patel, R. K., Khristi, S. M., Parikh, K. and Rajendran, G. 2012. Isolation and characterization of bacterial endophytes from Lycopersicon esculentum plant and their plant growth promoting characteristics. Nepal J. Biotechnol. 2:3752.

Paulitz, T. C., Park, C. S. and Baker, R. 1987. Biological control of Fusarium wilt of cucumber with nonpathogenic isolates of Fusarium oxysporum. Can. J. Microbiol. 33:349-353.

Posada, F. and Vega, F. E. 2006. Inoculation and colonization of coffee seedlings (Coffea arabica L.) with the fungal entomopathogen Beauveria bassiana (Ascomycota: Hypocreales). Mycoscience 47:284-289.

Prabhukarthikeyan, R., Saravanakumar, D. and Raguchander, T. 2014. Combination of endophytic Bacillus and Beauveria for the management of Fusarium wilt and fruit borer in tomato. Pest Manag. Sci. 70:1742-1750.

Premalatha, K. and Kalra, A. 2013. Molecular phylogenetic identification of endophytic fungi isolated from resinous and healthy wood of Aquilaria malaccensis, a red listed and highly exploited medicinal tree. Fungal Ecol. 6:205-211.

Radić, N. and Štrukelj, B. 2012. Endophytic fungi: the treasure chest of antibacterial substances. Phytomedicine 19:12701284.

Rai, M., Rathod, D., Agarkar, G., Dar, M., Brestic, M., Pastore, G. M. and Marostica, M. R. Jr. 2014. Fungal growth promotor endophytes: a pragmatic approach towards sustainable food and agriculture. Symbiosis 62:63-79.

Rania, A. B. A., Jabnoun-Khiareddine, H., Nefzi, A., Mokni-Tlili, S. and Daami-Remadi, M. 2016. Endophytic bacteria from Datura metel for plant growth promotion and bioprotection against Fusarium wilt in tomato. Biocontrol Sci. Technol. 26:1139-1165.

Raza, W., Ling, N., Zhang, R., Huang, Q., Xu, Y. and Shen, Q. 2017. Success evaluation of the biological control of Fusarium wilts of cucumber, banana, and tomato since 2000 and future research strategies. Crit. Rev. Biotechnol. 37:202-212.

Reis, A., Costa, H., Boiteux, L. S. and Lopes, C. A. 2005. First report of Fusarium oxysporum f. sp. lycopersici Race 3 on tomato in Brazil. Fitopatol. Bras. 30:426-428.

Saravanakumar, K., Yu, C., Dou, K., Wang, M., Li, Y. and Chen, J. 2016. Synergistic effect of Trichoderma-derived antifungal metabolites and cell wall degrading enzymes on enhanced biocontrol of Fusarium oxysporum f. sp. cucumerinum. Biol. Control 94:37-46.

Singh, P. P., Shin, Y. C., Park, C. S. and Chung, Y. R. 1999. Biological control of Fusarium wilt of cucumber by chitinolytic bacteria. Phytopathology 89:92-99.

Strobel, G. A. 2003. Endophytes as sources of bioactive products. Microbes Infect. 5:535-544.

Vethavalli, S. and Sudha, S. S. 2012. In vitro and in silico studies on biocontrol agent of bacterial strains against Fusarium oxysporum f. sp. lycopersici. Res. Biotechnol. 3:22-31.

Vos, C. M., Yang, Y., De Coninck, B. and Cammue, B. P. A. 2014. Fungal (-like) biocontrol organisms in tomato disease control. Biol. Control 74:65-81.

Wang, S., Liang, Y., Shen, T., Yang, H. and Shen, B. 2016. Biological characteristics of Streptomyces albospinus CT205 and its biocontrol potential against cucumber Fusarium wilt. Biocontrol Sci. Technol. 26:951-963.

Wiyakrutta, S., Sriubolmas, N., Panphut, W., Thongon, N., Danwisetkanjana, K., Ruangrungsi, N. and Meevootisom, V. 2004. Endophytic fungi with anti-microbial, anti-cancer and anti-malarial activities isolated from Thai medicinal plants. World J. Microbiol. Biotechnol. 20:265-272.

Worapong, J. and Strobel, G. A. 2009. Biocontrol of a root rot of kale by Muscodor albus strain MFC2. BioControl 54:301306.

Wu, L., Shang, H., Wang, Q., Gu, H., Liu, G. and Yang, S. 2016. Isolation and characterization of antagonistic endophytes from Dendrobium candidum Wall ex Lindl., and the biofertilizing potential of a novel Pseudomonas saponiphila strain. Appl. Soil Ecol. 105:101-108.

Xiang, L., Gong, S., Yang, L., Hao, J., Xue, M., Zeng, F., Zhang, X., Shi, W., Wang, H. and Yu, D. 2016. Biocontrol potential of endophytic fungi in medicinal plants from Wuhan Botanical Garden in China. Biol. Control 94:47-55.

Youssef, S. A., Tartoura, K. A. and Abdelraouf, G. A. 2016. Evaluation of Trichoderma harzianum and Serratia proteamaculans effect on disease suppression, stimulation of ROSscavenging enzymes and improving tomato growth infected by Rhizoctonia solani. Biol. Control 100:79-86.

Zeilinger, S., Gupta, V. K., Dahms, T. E. S., Silva, R. N., Singh, H. B., Upadhyay, R. S., Gomes, E. V., Tsui, C. K.-M. and Nayak, S. C. 2016. Friends or foes? Emerging insights from fungal interactions with plants. FEMS Microbiol. Rev. 40:182-207.

Zhang, Q., Zhang, J., Yang, L., Zhang, L., Jiang, D., Chen, W. and Li, G. 2014. Diversity and biocontrol potential of endophytic fungi in Brassica napus. Biol. Control 72:98-108. 